\title{
CANCER
}

\section{Cigarette smoking, appendectomy, and tonsillectomy as risk factors for the development of primary sclerosing cholangitis: a case control study}

\author{
S A Mitchell, M Thyssen, T R Orchard, D P Jewell, K A Fleming, R W Chapman
}

See end of article for authors' affiliations

......................

Correspondence to: Dr R W Chapman, Department of

Gastroenterology, Oxford Radcliffe Hospital, Oxford, UK; roger.chapman@ ndm.ox.ac.uk

Accepted for publication 5 March 2002

\begin{abstract}
Background and aims: The strong clinical association between primary sclerosing cholangitis (PSC) and ulcerative colitis (UC) suggests common factors in their pathogenesis. Smoking, previous appendectomy, and tonsillectomy have been associated with a decreased risk of developing UC. In this study, our aim was to examine these risk factors in patients with PSC with and without underlying inflammatory bowel disease (IBD).

Methods: The smoking habits and history of previous appendectomy and/or tonsillectomy of 170 patients with PSC, 41 without underlying IBD, 170 patients with UC but normal liver function tests, and 170 age and sex matched community controls were obtained by questionnaire.

Results: A total of 112 PSC patients (66\%) had never smoked compared with 66 controls (39\%). Only 12 PSC patients $(7 \%)$ were current smokers versus 43 controls $(25 \%)$. The resultant odds ratio of having PSC was 0.17 (95\% confidence interval (CI) 0.08-0.35) among current smokers and $0.33195 \%$ Cl 0.21-0.52) among ever (former+current) smokers. Among former smokers, the odds of having PSC were also significantly decreased (odds ratio $0.45,95 \% \mathrm{Cl} 0.26-0.73 ; \mathrm{p}<0.05$ ). In the subgroup of PSC patients without IBD, only $5 \%$ were current smokers versus $26 \%$ of matched controls, and never smokers were overrepresented $(68 \% \vee 37 \%)$. The rate of previous appendectomy was similar in all three study groups $(14 \%, 12 \%$, and $13 \%)$ but the frequency of tonsillectomy was reduced in the PSC group (21\% v $31 \% ; \mathrm{p}=0.05)$.

Conclusion: PSC, like UC, is a disease of non-smokers as the odds of having PSC was significantly decreased among current and former smokers. The association between non-smoking and PSC was independent of whether the PSC patient had underlying IBD. Previous tonsillectomy but not appendectomy may also be associated with a decreased risk of PSC but this warrants further study.
\end{abstract}

$\mathrm{P}$ rimary sclerosing cholangitis (PSC) is a chronic cholestatic liver disease characterised by a progressive obliterating inflammatory fibrosis of the intrahepatic and extrahepatic bile ducts. Loss of functioning bile ducts leads to biliary cirrhosis and eventually hepatic failure. The cause is unknown but the observation of abnormal immune regulation and genetic associations ${ }^{1}$ with particular class I and II HLA genes suggests an immune mediated basis for this disease. The prevalence of ulcerative colitis (UC) in patients with PSC has been reported as $44-98 \% .^{2-5}$ Conversely, about $2-5 \%$ of patients with UC have concomitant PSC. ${ }^{67}$ The strong clinical association between PSC and UC suggests common factors in the pathogenesis of both diseases.

The cause of UC is also unknown but two environmental factors have been associated with a decreased risk of developing this disease. Firstly, a number of case control studies, ${ }^{8}$ listed in table $1,{ }^{9-13}$ have shown that current smokers are less likely to develop UC than non-smokers and suggest that smoking offers a protective effect against the development of UC. Patients with UC who are ex-smokers usually develop the disease within a few years after they stop smoking ${ }^{14}$ but the evidence that former smokers are at increased risk of developing UC compared with those who have never smoked is conflicting..$^{10-12}$ Although the constituents of cigarette smoke responsible for the protective effect have not been identified, a placebo controlled randomised trial showed that transdermal nicotine used in the treatment of active UC produced clinical, endoscopic, and histological improvement. ${ }^{15}$ In contrast, a recent open label small pilot study of transdermal nicotine in PSC showed no benefits in terms of symptoms or liver biochemistry. ${ }^{16}$

Secondly, a negative association has been reported between previous appendectomy and the risk of developing $\mathrm{UC}^{17}$ (see table 1). ${ }^{18-26}$ Although some of the studies did not distinguish between primary appendectomy (surgery for appendicitis) and incidental removal of the appendix for other reasons (such as during a colectomy), the risk of developing UC was 2-50 times lower in subjects who had undergone appendectomy compared with subjects with the appendix in situ. If appendectomy protects against the development of UC, then removal of other mucosa associated lymphoid tissue such as the tonsils may offer a similar protective effect.

In the present control study we compared the smoking habits and history of previous appendectomy and/or tonsillectomy in a group of patients with PSC with a group of patients with UC and a control group. The purpose of the study was to determine if the relationship between PSC and cigarette smoking is similar to that found between smoking and UC and to examine if any effect of cigarette smoking on PSC is independent of the effect of cigarette smoking on UC. We also wished to determine if the surgical procedures appendectomy and tonsillectomy, which may deplete the mucosal associated lymphoid tissue, are protective against the development of PSC.

\section{PATIENTS AND METHODS}

\section{Subjects}

A total of 176 patients with PSC were identified: 99 patients under follow up in the liver and inflammatory bowel disease

Abbreviations: PSC, primary sclerosing cholangitis; UC, ulcerative colitis; IBD, inflammatory bowel disease. 
Table 1 Studies of smoking behaviour and appendectomy and the risk of developing ulcerative colitis (UC) or primary sclerosing cholangitis (PSC)

\begin{tabular}{|c|c|c|c|c|c|c|}
\hline Study & Country & Disease & $\begin{array}{l}\text { No of patients } \\
\text { (n) }\end{array}$ & $\begin{array}{l}\text { OR* of current } \\
\text { smoker having } \\
\text { UC/PSC }\end{array}$ & $\begin{array}{l}\text { OR* of former } \\
\text { smokers having } \\
\text { UC/PSC }\end{array}$ & $\begin{array}{l}\text { OR† of developing } \\
\text { UC/PSC after } \\
\text { appendectomy }\end{array}$ \\
\hline Tobin $1987^{\circ}$ & UK & UC & 280 & 0.2 & $1.1 \ddagger$ & \\
\hline Boyko $1987^{10}$ & USA & UC & 212 & 0.6 & 1.9 & \\
\hline Lindberg $1988^{11}$ & Sweden & UC & 260 & 0.6 & 2.1 & \\
\hline Nakamura $1994^{13}$ & Japan & UC & 384 & 0.3 & 1.67 & \\
\hline Rutgeerts $1994^{17}$ & Belgium & UC & 174 & & & 0.02 \\
\hline Silverstein $1994^{12}$ & USA & UC & 100 & 0.13 & $1.2 \ddagger$ & \\
\hline Smithson $1995^{18}$ & UK & UC & 197 & & & 0.2 \\
\hline Loftus $1996^{28}$ & USA & PSC & 184 & 0.13 & $0.62 \ddagger$ & \\
\hline \multirow{2}{*}{ Van Erpecum $1996^{27}$} & Netherlands & PSC & 59 & 0.37 & $0.92 \ddagger$ & $1.44 \ddagger$ \\
\hline & & UC & 130 & 0.23 & 2.86 & $0.64 \ddagger$ \\
\hline Minocha $1997^{20}$ & USA & UC & 193 & & & 0.25 \\
\hline Parrello $1997^{19}$ & Italy & UC & 536 & & & 0.3 \\
\hline Russel $1997^{21}$ & Netherlands & UC & 232 & 0.5 & & 0.36 \\
\hline Duggan $1998^{22}$ & UK & UC & 213 & & & 0.2 \\
\hline Dijkstra $1999^{23}$ & New Zealand & UC & 75 & & & 0.32 \\
\hline Koutroubakis $1999^{24}$ & Greece & UC & 134 & & & $0.6 \ddagger$ \\
\hline Reif $2000^{47}$ & Israel & UC & 273 & 0.5 & $1.2 \ddagger$ & \\
\hline Naganuma $2001^{26}$ & Japan & UC & 325 & & & 0.35 \\
\hline Reif $2001^{36}$ & Israel & UC & 271 & & & $0.7 \ddagger$ \\
\hline
\end{tabular}

*Odds ratio of current/former smokers having the disease (UC or PSC) relative to never smokers.

†Odds ratio of patients following appendectomy having the disease (UC or PSC) relative to patients with an appendix in situ.

$\ddagger$ Result is not significant, otherwise all other results are significant $(p<0.05)$.

(IBD) clinics and/or on the PSC database at the Oxford Radcliffe Hospital and 77 members of the National PSC Patient Group under the care of a variety of institutions. A questionnaire was sent to all patients during the period August 1997 to January 1999. Two patients (from the National PSC Group) were excluded from the study because the diagnosis of PSC was uncertain (based on clinical features only). Four patients were excluded because their general practitioner was unable to provide a list of suitable control subjects, as detailed below. All 170 patients included in this study had a diagnosis of PSC based on established clinical, biochemical, and radiological criteria. The majority of patients under the care of the Oxford Radcliffe Hospital and most of the others had also undergone at least one liver biopsy for diagnostic and staging purposes. One hundred and twenty nine patients $(76 \%)$ had underlying IBD of whom $116(68 \%)$ had UC and $13(8 \%)$ had Crohn's disease. Two thirds of PSC patients were male. Other characteristics of the patients are given in table 2 .

A total of 170 patients with a diagnosis of UC, matched for age, sex, and area of residence to the PSC patients were selected from the IBD database at the Oxford Radcliffe Hospital. UC patients with abnormal liver function tests were excluded from this cohort. Where a suitable match proved impossible, the PSC patient's general practitioner (primary physician) was asked to provide the name and contact details of the next same sex patient alphabetically in his practice with a diagnosis of UC and of a similar age (within a five year band) to the PSC patient. If it proved impossible to obtain a reply from the first UC patient identified, the next patient age and sex matched to the index PSC patient was contacted. We found that 153 (90\%) first named UC patients replied and only 17 could not be contacted or declined. All 17 of the second named UC patients answered.

No institutional or clinic based controls were used. Instead the general practitioner (primary physician) of each PSC patient was contacted and asked to provide the name and contact details of the next three same sex but unrelated patients listed alphabetically on his practice list of a similar age (within a five year band) to the index PSC patient. Only four general practitioners were unable to provide a list of control subjects and as a result four PSC patients were excluded from the study. The first named control subject was contacted and if a reply was not received after four attempts (two mail, two by telephone) or the subject declined, the second named control subject was contacted, and so on. We found that 152 first named controls (90\%) replied, the remainder either could not be contacted or declined. Fourteen of 18 of the second named controls participated and it was only necessary to

Table 2 Characteristics of the primary sclerosing cholangitis (PSC), ulcerative colitis (UC), and control groups

\begin{tabular}{lccc}
\hline & PSC & UC & Controls \\
\hline $\mathrm{n}$ & 170 & 170 & 170 \\
Male & $111(65 \%)$ & $111(65 \%)$ & $111(65 \%)$ \\
Age (y) (mean (SD)) & $53(14)$ & $55(14)$ & $54(14)$ \\
Age at diagnosis (y) (mean (SD)) & $40(16)$ & $34(12)$ & $\mathrm{N} / \mathrm{A}$ \\
IBD & $129(76 \%)$ & $170(100 \%)$ & $0(0 \%)$ \\
UC & $116(68 \%)^{*}$ & $170(100 \%) \dagger$ & $0(0 \%)$ \\
Crohn's disease & $13(8 \%)$ & $0(0 \%)$ & $0(0 \%)$ \\
No IBD & $41(24 \%)$ & $0(0 \%)$ & $0(0 \%)$ \\
\hline
\end{tabular}

*Total colitis in $92(79 \%)$, left sided in $14(12 \%)$, and unknown in $10(9 \%)$.

tTotal colitis in $120(71 \%)$, left sided in $38(22 \%)$, and unknown in $12(7 \%)$.

N/A, not applicable. 
Table 3 Relationship between smoking habit, appendectomy, or tonsillectomy, and all patients with primary sclerosing cholangitis (PSC)

\begin{tabular}{|c|c|c|c|c|c|}
\hline & PSC & Controls* & Odds ratiof & $95 \% \mathrm{Cl}$ & $p$ Value \\
\hline \multicolumn{6}{|l|}{ Smoking } \\
\hline Never & $112(66 \%)$ & $66(39 \%)$ & 1.0 & & \\
\hline Ever & 58 (34\%) & $104(61 \%)$ & 0.33 & $0.21-0.52$ & $<0.001$ \\
\hline Former & $46(27 \%)$ & 61 (36\%) & 0.45 & $0.26-0.73$ & $<0.05$ \\
\hline Current & 12 (7\%) & $43(25 \%)$ & 0.17 & $0.08-0.35$ & $<0.001$ \\
\hline \multicolumn{6}{|c|}{ Appendectomy } \\
\hline No & $146(86 \%)$ & $148(87 \%)$ & & & \\
\hline Yes & 24 (14\%) & $22(13 \%)$ & 1.11 & $0.57-2.2$ & NS \\
\hline \multicolumn{6}{|c|}{ Tonsillectomy } \\
\hline No & 135 (79\%) & 117 (69\%) & & & \\
\hline Yes & 35 (21\%) & 53 (31\%) & 0.57 & $0.34-0.96$ & 0.05 \\
\hline
\end{tabular}

contact the third named control in four cases. None of the control subjects had underlying IBD.

\section{Data collection}

Detailed smoking information was obtained via a specially designed and ethically approved questionnaire. All subjects (PSC, UC, and controls) received identical questionnaires.

The questionnaire included sections on:

- Demographic details

- Brief medical history

- Current smoking habits (duration, amount, type)

- Previous smoking habits (duration, amount, type, date, and reason for cessation)

- Previous history of surgery (appendectomy, tonsillectomy, splenectomy, colectomy, other)

\section{- Occupation}

Based on this questionnaire, PSC and UC patients and controls were divided into never, former, or current smokers and into subjects with or without a previous history of appendectomy or tonsillectomy.

\section{Statistical analysis}

The relative frequencies of smoking behaviour, appendectomy, and tonsillectomy between study groups are expressed as odds ratios based on a matched 1:1 conditional logistic regression model. The corresponding 95\% confidence intervals (CI) are given. A separate analysis was performed on the PSC group depending on the presence or absence of IBD. PSC patients with underlying Crohn's disease were not subjected to a separate analysis because of the small sample size but these patients were included in the analysis of the whole PSC group.

To determine whether a significant prevalence versus incidence bias could be a confounding factor in this study, the relative frequencies of smoking behaviour, appendectomy, and tonsillectomy were also analysed in each study group stratified according to the duration between time of diagnosis and collection of the data (completion of the questionnaire). A similar analysis was performed with patients in each in the PSC groups stratified according to whether they were recruited from the hospital PSC database or through their membership of the National PSC Patient Support Group.

\section{RESULTS}

Fifty six per cent of PSC patients included in the study were recruited from the liver and IBD clinics at the Oxford Radcliffe Hospital while the remainder were members of the National PSC Support Group. Also included were 170 UC patients and control subjects matched for sex, age ( \pm 5 years), and geographical locality. Approximately two thirds of PSC patients and hence the matched UC patients and controls were male. Three quarters of PSC patients had underlying IBD; the majority had UC (68\%) and a small number had Crohn's colitis $(8 \%)$. In PSC patients with IBD, most had total colitis (79\%). In $86 \%$ of PSC patients with IBD, UC or Crohn's had been diagnosed prior to the development of their liver disease. In $10 \%$ of patients, PSC was diagnosed at the time of their first presentation with IBD while a diagnosis of IBD only occurred after that of PSC in 4\%.

Forty one patients with PSC (24\%) included in this study had no underlying IBD. Thirty of these patients had at least one colonoscopy with a series of biopsies (median per patient 1, range 1-3). The remainder had at least one flexible sigmoidoscopy with a biopsy series and a barium enema (median per patient 1 , range $1-4$ ). To show that the absence of a concurrent diagnosis of IBD was not related to short and inadequate follow up, the median duration of follow up after the first hospital visit was noted to be 8.5 years in PSC patients without IBD compared with a median of 5.5 years in PSC patients with IBD.

\section{Smoking habits}

The frequency of cigarette smoking among all PSC patients compared with their matched controls is given in table 3. A total of 112 PSC patients (66\%) had never smoked compared with 66 controls (39\%). Only 12 PSC patients (7\%) were current smokers versus 43 controls $(25 \%)$. The resultant odds ratio was 0.17 (95\% CI 0.08-0.35) for current smokers and 0.33 (95\% CI $0.21-0.52$ ) for ever (former+current) smokers. If smoking habits were analysed separately in PSC patients with and without IBD, as in table 4, even fewer current smokers $(5 \% \vee 26 \%)$ and greater numbers of never smokers $(68 \% v$ $37 \%)$ were noted in patients with PSC alone compared with controls. To exclude the possibility that the paucity of current smokers among PSC patients may have resulted from patients changing their smoking habits due to concern about their liver disease, the questionnaire asked patients their reason for cessation of smoking. Forty two of the 46 former smokers (91\%) ceased smoking more than a year prior to their diagnosis of PSC for a variety of reasons, usually unrelated to health concerns. Compared with never smokers, the odds of having PSC alone was one tenth and of having PSC and IBD one fifth as great among current smokers $(\mathrm{p}<0.05$ and $<0.001$, respectively). There were also significantly decreased odds of having PSC with IBD among former smokers $(p<0.05$, table 3$)$. There were insufficient numbers of PSC patients with Crohn's disease to analyse these separately.

Table 5 gives the frequency of cigarette smoking among PSC patients compared with their matched controls stratified according to the time from diagnosis to participation in this study (0-6 years; $7-12$ years; over 12 years). Although the 
Table 4 Smoking habits in patients with primary sclerosing cholangitis (PSC) and inflammatory bowel disease (IBD) (ulcerative colitis or Crohn's, $n=129$ ) compared with matched controls, and smoking habits in patients with PSC but without IBD $(n=41)$ compared with matched controls

\begin{tabular}{llllll}
\hline & PSC & Controls* & Odds ratiot & $95 \% \mathrm{Cl}$ & $\mathrm{p}$ Value \\
\hline Smoking in PSC with IBD & & & & & \\
$\quad$ Never & $84(65 \%)$ & $51(40 \%)$ & 1.0 & & \\
$\quad$ Ever & $45(35 \%)$ & $78(60 \%)$ & 0.35 & $0.2-0.6$ & $<0.001$ \\
$\quad$ Former & $35(27 \%)$ & $46(35 \%)$ & 0.46 & $0.25-0.8$ & $<0.05$ \\
$\quad$ Current & $10(8 \%)$ & $32(25 \%)$ & 0.19 & $0.08-0.44$ & $<0.001$ \\
Smoking in PSC without IBD & & & & & \\
$\quad$ Never & $28(68 \%)$ & $15(37 \%)$ & 1.0 & & \\
$\quad$ Ever & $13(32 \%)$ & $26(63 \%)$ & 0.29 & $0.12-0.8$ & $<0.05$ \\
$\quad$ Former & $11(27 \%)$ & $15(37 \%)$ & 0.39 & $0.1-1.2$ & $\mathrm{NS}$ \\
$\quad$ Current & $2(5 \%)$ & $11(26 \%)$ & 0.10 & $0.01-0.5$ & $<0.05$ \\
\hline
\end{tabular}

* Controls matched to PSC patients in terms of age/sex/locality. †Odds of having PSC relative to never smokers.

Table 5 Relationship between smoking habit and all patients with primary sclerosing cholangitis (PSC) stratified according to time from diagnosis to completion of questionnaire, $0-6$ years $(n=50), 7-12$ years $(n=56)$, and $>12$ years $(n=64)$

\begin{tabular}{lllllll}
\hline $\begin{array}{l}\text { Time from } \\
\text { diagnosis to } \\
\text { completion of } \\
\text { questionnaire }\end{array}$ & Smoking habit & PSC & Controls* & Odds ratiot & $95 \%$ Cl & p Value \\
\hline $0-6 y$ & Never & $34(68 \%)$ & $20(40 \%)$ & 1.0 & & \\
& Ever & $16(32 \%)$ & $30(60 \%)$ & 0.31 & $0.13-0.77$ & $<0.01$ \\
& Former & $14(28 \%)$ & $18(36 \%)$ & 0.46 & $0.17-1.22$ & 0.1 \\
$7-12 y$ & Current & $2(4 \%)$ & $12(24 \%)$ & 0.1 & $0.01-0.54$ & $<0.01$ \\
& Never & $37(66 \%)$ & $22(39 \%)$ & 1.0 & & \\
& Ever & $19(34 \%)$ & $34(61 \%)$ & 0.33 & $0.14-0.77$ & $<0.05$ \\
$>12 y$ & Former & $16(29 \%)$ & $20(36 \%)$ & 0.48 & $0.19-1.2$ & 0.1 \\
& Current & $3(5 \%)$ & $14(25 \%)$ & 0.13 & $0.03-0.55$ & $<0.01$ \\
& Never & $41(64 \%)$ & $24(37 \%)$ & 1.0 & & \\
& Ever & $23(36 \%)$ & $40(63 \%)$ & 0.34 & $0.15-0.73$ & $<0.01$ \\
& Former & $16(25 \%)$ & $23(36 \%)$ & 0.41 & $0.17-0.99$ & $<0.05$ \\
& Current & $7(11 \%)$ & $17(27 \%)$ & 0.24 & $0.08-0.73$ & $<0.01$
\end{tabular}

*Controls matched to PSC patients in terms of age/sex/locality.

†Odds of having PSC relative to never smokers.

number of patients included in each of the levels of stratification was inevitably small, the odds of having PSC among current and ever (current+former) smokers was significantly decreased in all three stratification groups. In a separate analysis, the smoking habits of patients recruited from the PSC database were comparable with those patients recruited from the National PSC Patient Support Group.

The frequency of current smoking among UC patients $(12 \%)$ was also significantly decreased compared with controls $(25 \%)(p<0.05$, table 6$)$. Subgroup analysis according to the extent of colitis showed no difference in smoking habits between patients with left sided colitis compared with total colitis (data not shown). Similarly, smoking habits remained unchanged with increasing duration of disease (stratification according to length of symptoms, data not shown). In contrast with the PSC group, there was no significant decrease in the numbers of former smokers in the UC group compared with controls, although the odds of having UC was significantly reduced among UC patients who had ever smoked.

\section{Appendectomy}

Thirty five PSC patients (20\%) and 30 UC patients (18\%) had undergone an appendectomy compared with 22 controls (13\%). Eleven PSC patients and 10 UC patients had appendectomy as part of a colectomy after the diagnosis of UC. Once these had been excluded, the frequency of primary appendectomy was similar among PSC (14\%), UC (12\%), and control
(13\%) groups. The odds ratio for previous appendectomy was 1.11 (95\% CI 0.57-2.2) and 0.9 (95\% CI 0.45-1.79) in the PSC and UC groups, respectively. Following stratification of PSC and UC patients for time since diagnosis, the frequency of primary appendectomy was similar in each group.

\section{Tonsillectomy}

Compared with controls, the frequency of previous tonsillectomy was significantly reduced in the PSC group $(21 \% \vee 31 \%$; odds ratio $0.57,95 \%$ CI $0.34-0.96, p=0.05$ ) but not in the UC group. When the PSC group was stratified according to duration of disease, the frequency of previous tonsillectomy was significantly decreased compared with controls only in PSC patients in the over 12 years from diagnosis group ( $17 \%$ v $34 \%$; odds ratio $0.4,95 \%$ CI $0.16-0.98, \mathrm{p}<0.05$ ). All reported tonsillectomies preceded the diagnosis of PSC or UC.

\section{DISCUSSION}

The principle finding of our case control study of smoking habits in PSC patients with and without IBD was that fewer PSC patients currently smoke or have ever smoked than controls. This observation has been previously reported in both PSC and UC. ${ }^{9} 12172728$ Previous studies have however failed to show that the inverse association between current smoking and PSC is independent of and not secondary to the protective effect of smoking on UC. ${ }^{27}{ }^{28}$ In this study the odds of having PSC with and without IBD was significantly decreased among 
Table 6 Relationship between smoking habit, appendectomy, or tonsillectomy, and patients with ulcerative colitis (UC) only

\begin{tabular}{|c|c|c|c|c|c|}
\hline & UC & Controls* & Odds ratio $†$ & $95 \% \mathrm{Cl}$ & $p$ Value \\
\hline \multicolumn{6}{|l|}{ Smoking } \\
\hline Never & 88 (52\%) & 66 (39\%) & 1.0 & & \\
\hline Ever & 82 (48\%) & 104 (61\%) & 0.59 & $0.38-0.92$ & $<0.05$ \\
\hline Former & $62(36 \%)$ & 61 (36\%) & 0.76 & $0.46-1.26$ & NS \\
\hline Current & 20 (12\%) & $43(25 \%)$ & 0.35 & $0.18-0.68$ & $<0.05$ \\
\hline \multicolumn{6}{|c|}{ Appendectomy } \\
\hline No & $150(88 \%)$ & 148 (87\%) & & & \\
\hline Yes & 20 (12\%) & 22 (13\%) & 0.9 & $0.45-1.79$ & NS \\
\hline \multicolumn{6}{|c|}{ Tonsillectomy } \\
\hline No & 125 (74\%) & 117 (69\%) & & & \\
\hline Yes & 45 (26\%) & 53 (31\%) & 0.79 & $0.48-1.71$ & NS \\
\hline
\end{tabular}

current smokers and those who have ever smoked compared with never smokers. In the present study, current smokers were 10 times less likely to develop PSC without IBD, five times less likely to develop PSC and IBD, but only three times less likely to develop UC alone compared with never smokers. Ever (current+former) smokers were just over three times less likely to develop PSC without IBD, two and a half times less likely to develop PSC and IBD, but only one and a half times less likely to develop UC alone compared with never smokers. Former smokers were also less likely to develop PSC. In this study the risk of former smokers developing UC was not significantly decreased nor was it significantly increased, as suggested in some studies. ${ }^{10} 11{ }^{13}$ Smoking offers greater protection against developing PSC than UC. The protective effect of smoking on the development of PSC cannot be attributed solely to the inverse association between smoking and UC but is, at least in part, independent of it.

To exclude the possibility that the inverse relationship between smoking and PSC may be explained by PSC patients altering their smoking habits after they were diagnosed, we examined the timing of smoking cessation in former smokers. The majority of former smokers in both the PSC and UC groups ceased smoking more than one year before the diagnosis of either PSC or UC was made. Furthermore, in both the PSC and UC groups never smokers as opposed to former smokers were overrepresented. In the PSC group the odds ratio of having PSC among former smokers was significantly reduced compared with never smokers. The protective effect of smoking on the development of PSC or UC could not be attributed to alterations in smoking habits following diagnosis in these patient groups.

In case control studies selection of controls is important. Previous studies of smoking and PSC have used institutional or clinic based controls. ${ }^{27}{ }^{28}$ Although matched to PSC patients for age and sex, both important factors influencing smoking behaviour, the use of clinic based controls in these studies may have artificially increased the rate of current smokers in the control group and so exaggerated the reduced risk of PSC among current smokers. Certainly in the Dutch study ${ }^{27}$ a much higher percentage of current smokers was reported in the control group than in the present study (38\% v 25\%). This difference may be explained in part by variations in national smoking habits although selection bias cannot be excluded. In the present study controls were obtained from the PSC patients' community, were identified using the same criteria by practitioners who were not involved in the study, and as a consequence were matched not only for age and sex but also for geographical locality. Inclusion of a high proportion (44\%) of PSC patients from outside the region and matching their controls to their locality reduces the potential effect of referral bias on our results. The same questionnaire was posted to all three groups and data were collected from these and not the clinic notes to avoid the risk of data collection bias.

Although the subgroup of PSC patients without IBD was small in number, we believe the lower than expected numbers of current smokers in this group indicates a genuine protective effect of smoking on the development of PSC. Crucial in the assessment of whether smoking has an independent effect on the development of PSC is to identify sufficient numbers of subjects with PSC but without underlying UC. The diagnosis of UC must be confidently excluded in the PSC population. Data from the studies of Perdigoto and colleagues ${ }^{29}$ and others suggest that in PSC, UC is quiescent in the majority, and in nearly a quarter of PSC patients the rectum is spared. Double contrast barium enema alone is insufficient to screen for UC; flexible sigmoidoscopy to the splenic flexure is a minimum requirement although full colonoscopy with biopsies is preferable. Three quarters of patients within our "PSC without IBD group" had at least one full colonoscopy with a biopsy series. All of the remainder had at least one flexible sigmoidoscopy with a biopsy series and double contrast barium enema. None of the patients reported symptoms of or developed signs of colitis in a median follow up period of 8.5 years. As asymptomatic UC in PSC is rare ${ }^{29}$ and all patients had at least one endoscopic evaluation of their colon, we were confident that UC had been excluded in this subgroup.

Given that PSC is a relatively uncommon liver disease, we used prevalent cases in this case control study. Such a strategy may introduce prevalence bias as a result of the time gap between onset of the condition and selection of subjects for the study where a high proportion have already died due to the severity of the condition or related complications. The natural history of PSC is variable and unpredictable although the three largest studies ${ }^{40}{ }^{31}$ have all shown an estimated median survival of 12 years in symptomatic patients. But nearly half of patients are asymptomatic at diagnosis ${ }^{31}$ and even though most will eventually develop progressive disease, their survival rate remains in excess of $70 \%$ at 16 years from diagnosis. ${ }^{32}$ While the development of cholangiocarcinoma can complicate the course of the disease in $6-15 \%$ of PSC patients, ${ }^{5}$ the annual incidence in PSC is low ( $1 \%$ or less). ${ }^{33}$ PSC patients who are current or former smokers are at increased risk of developing hepatobiliary cancer. ${ }^{34}$

To determine if prevalence bias may be a confounding factor in this study we stratified the study groups according to time from diagnosis to completion of the questionnaire and examined the association between smoking habits and history of previous appendectomy and/or tonsillectomy with each individual stratum. The odds of having PSC among current and ever (current+former) smokers was significantly decreased in all three stratification groups and there was no significant difference in the proportion who had never smoked 
between the groups. If this study were merely identifying smoking as a prognostic factor, we would expect an excess of patients who had never smoked in the group over 12 years from diagnosis. The absence of any significant difference in smoking habits within the three stratification groups suggests that time from diagnosis to inclusion in this study was not a confounding variable and there was no prevalence bias in this study.

A number of case control studies have shown a weak negative association ${ }^{18-23} 26$ between previous appendectomy and the risk of developing UC. A recent cohort study $y^{35}$ found that appendectomy for an inflammatory condition (appendicitis or lymphadenitis) but not for non-specific abdominal pain was associated with a lower risk of subsequent UC. Although some of the studies did not distinguish between primary appendectomy (surgery for appendicitis) and removal of the appendix during another procedure (such as colectomy) the risk of developing UC was 2-50 times lower in subjects who had undergone appendectomy compared with subjects with the appendix in situ. In several studies, ${ }^{19}{ }^{22}{ }^{23}$ including Rutgeerts' study ${ }^{17}$ in Belgium showing a stronger negative association (relative risk of UC developing in subjects after appendectomy was 29 times lower relative to the risk in subjects with the appendix intact), the appendectomy rate in the control group was very high. The appendectomy rate in our control group (13\%) was close to the prevalence reported in several British studies (15\%). We were unable to demonstrate a significantly lower frequency of patients with a history of previous appendectomy in either the PSC or UC group versus controls.

It is proposed that appendectomy may protect against the development of UC by depletion of mucosal helper T cells with alteration in the balance between helper and suppressor $\mathrm{T}$ cells. If appendectomy offers such protection, removal of other mucosa associated lymphoid tissue such as the tonsils may offer a similar protective effect. A number of studies have shown that tonsillectomy does not influence the occurrence or mode of presentation of UC..$^{18-202436}$ Mucosal T cell activity has an even more critical role in the pathogenesis of coeliac disease but one study has shown that resection of mucosa associated lymphoid tissue does not influence the occurrence or mode of presentation of adult coeliac disease. ${ }^{37}$ We found a marginal but significant reduction in the frequency of previous tonsillectomy in the PSC group (21\% v31\%; $\mathrm{p}=0.05)$ but not in the UC group. When patients were stratified according to time from diagnosis to completion of the questionnaire, the frequency of previous tonsillectomy was significantly decreased compared with controls only in PSC patients in the over 12 years from diagnosis group ( $17 \%$ v $34 \%$; $\mathrm{p}<0.05)$. Although this finding may suggest a small protective effect of tonsillectomy on the development of PSC, tonsillectomy generally occurs in childhood or early adulthood and we were not able to exclude recall bias by cross checking whether patients had a tonsillectomy with another source other than their questionnaire. We believe that the relationship between previous tonsillectomy and PSC warrants further investigation.

The present study does not offer any conclusions on the mechanism by which smoking offers protection against the development of PSC and UC. A number of potential mechanisms have been identified in smokers, including alterations in cell mediated ${ }^{38}$ and humoral immunity, intestinal permeability, ${ }^{40}$ colonic mucus production, ${ }^{41}$ mucosal blood flow, ${ }^{42}$ mucosal eicosanoids, ${ }^{43}{ }^{44}$ cytokines, ${ }^{45}$ and the adrenal axis. ${ }^{46}$ The close clinical relationship between PSC and UC, and the observed negative association between smoking and both diseases suggests that smoking may act through its effects on the cellular and humoral immune system although its effects on the adrenal axis, eicosanoid levels, colonic mucus production, mucosal blood flow, and intestinal permeability may be equally relevant. The independent protective effect of smoking on the development of PSC may rekindle interest in the pathogenesis of PSC in relation to the pathogenesis of IBD and the role of environmental factors such as smoking.

In conclusion, the present case control study shows that PSC like UC is a disease of non-smokers and that smoking has a protective effect on the development of PSC which is independent of whether or not the PSC patient has underlying IBD. Previous tonsillectomy but not appendectomy may also have a protective role but this warrants further study.

\section{Authors' affiliations}

S A Mitchell, M Thyssen, T R Orchard, D P Jewell, R W Chapman, Department of Gastroenterology, Oxford Raddliffe Hospital, Oxford, UK K A Fleming, Nuffield Department of Pathology and Bacteriology, University of Oxford, Oxford, UK

\section{REFERENCES}

1 Spurkland A, Saarinen S, Boberg KM, et al. HLA class II haplotypes in primary sclerosing cholangitis patients from five European populations. Tissue Antigens 1999;53:459-69.

2 Escorsell A, Parés A, Rodés J, et al. Epidemiology of primary sclerosing cholangitis in Spain. Spanish Association for the Study of the Liver. J Hepatol 1994;21:787-91.

3 Fausa O, Schrumpf E, Elgjo K. Relationship of inflammatory bowel disease and primary sclerosing cholangitis. Semin Liver Dis $1991 ; 11: 31-9$

4 Wiesner RH, Grambsch PM, Dickson ER, et al. Primary sclerosing cholangitis: natural history, prognostic factors and survival analysis. Hepatology 1989;10:430-6.

5 Schrumpf E, Abdelnoor M, Fausa $O$, et al. Risk factors in primary sclerosing cholangitis. J Hepatol 1994;21:1061-6.

6 Olsson R, Danielsson A, Järnerot $G$, et al. Prevalence of primary sclerosing cholangitis in patients with ulcerative colitis. Gastroenterology 1991;100:1319-23.

7 Shepherd HA, Selby WS, Chapman RW, et al. Ulcerative colitis and persistent liver dysfunction. Q J Med 1983;52:503-13.

8 Logan RF, Edmond M, Somerville KW, et al. Smoking and ulcerative colitis. BM (Clin Res Ed) 1984;288:751-3

9 Tobin MV, Logan RF, Langman M, et al. Cigarette smoking and inflammatory bowel disease. Gastroenterology 1987:93:316-21.

10 Boyko EJ, Koepsell TD, Perera DR, et al. Risk of ulcerative colitis among former and current cigarette smokers. N Engl J Med 1987;316:707-10.

11 Lindberg E, Tysk C, Andersson K, et al. Smoking and inflammatory bowel disease. A case control study. Gut 1988;29:352-7.

12 Silverstein MD, Lashner BA, Hanaver SB. Cigarette smoking and ulcerative colitis: a case-control study. Mayo Clin Proc 1994;69:425-9.

13 Nakamura Y, Labarthe DR. A case-control study of ulcerative colitis with relation to smoking habits and alcohol consumption in Japan. Am J Epidemiol 1994;140:902-11.

14 Motley RJ, Rhodes J, Ford GA, et al. Time relationships between cessation of smoking and onset of ulcerative colitis. Digestion 1987;37:125-7

15 Sandborn WJ, Tremaine WJ, Offord KP, et al. Transdermal nicotine for mildly to moderately active ulcerative colitis. A randomized, double-blind, placebo-controlled trial. Ann Intern Med 1997;126:364-71.

16 Angulo $P$, Bharucha $A E$, Jorgensen RA, et al. Oral nicotine in treatment of primary sclerosing cholangitis: a pilot study. Dig Dis Sci 1999;44:602-7.

17 Rutgeerts $\mathbf{P}$, Haens $G$, Hiele $M$, et al. Appendectomy protects against ulcerative colitis. Gastroenterology 1994;106:1251-3.

18 Smithson JE, Radford SG, Jewell DP. Appendectomy and tonsillectomy in patients with inflammatory bowel disease. J Clin Gastroenterol 1995;21:283-6.

19 Parrello T, Pavia M, Angelillo IF, et al. Appendectomy is an independent protective factor for ulcerative colitis: results of a multicentre case control study. The Italian Group for the Study of the Colon and Rectum (GISC). Ital J Gastroenterol Hepatol 1997;29:208-1 1

20 Minocha A, Raczkowski CA. Role of appendectomy and tonsillectomy in pathogenesis of ulcerative colitis. Dig Dis Sci 1997:42:1567-9.

21 Russel MG, Dorant E, Brummer RJ, et al. Appendectomy and the risk of developing ulcerative colitis or Crohn's disease: results of a large case-control study. South Limburg Inflammatory Bowel Disease Study Group. Gastroenterology 1997;1 13:377-82.

22 Duggan AE, Usmani I, Neal KR, et al. Appendicectomy, childhood hygiene, Helicobacter pylori status, and risk of inflammatory bowel disease: a case control study. Gut 1998;43:494-8.

23 Dijkstra B, Bagshaw PF, Frizelle FA. Protective effect of appendectomy on the development of ulcerative colitis: matched, case-control study. Dis Colon Rectum 1999:42:334-6.

24 Koutroubakis IE, Vlachonikolis IG, Kapsoritakis A, et al. Appendectomy, tonsillectomy, and risk of inflammatory bowel disease: case-controlled study in Crete. Dis Colon Rectum 1999:42:225-30.

25 Koutroubakis IE, Vlachonikolis IG. Appendectomy and the developmen of ulcerative colitis: results of a metaanalysis of published case-control studies. Am J Gastroenterol 2000;95:171-6. 
26 Naganuma $\mathbf{M}$, Lizuka B, Torii $A$, et al. Appendectomy protects against the development of ulcerative colitis and reduces its recurrence: results of a multicenter case-controlled study in Japan. Am J Gastroenterol 2001;96:1123-6.

27 van Erpecum KJ, Smits SJ, van de Meeberg PC, et al. Risk of primary sclerosing cholangitis is associated with nonsmoking behavior. Gastroenterology 1996;110:1503-6.

28 Loftus EVJ, Sandborn WJ, Tremaine WJ, et al. Primary sclerosing cholangitis is associated with nonsmoking: a case-control study. Gastroenterology 1996;110:1496-502.

29 Perdigoto R, Wiesner RH, La Russo et al. Inflammatory bowel disease associated with primary sclerosing cholangitis. Gastroenterology 1991; 100:A238.

30 Farrant JM, Hayllar KM, Wilkinson ML, et al. Natural history and prognostic variables in primary sclerosing cholangitis. Gastroenterology 1991;100:1710-17.

31 Broomé U, Olsson R, Lööf $L$, et al. Natural history and prognostic factors in 305 Swedish patients with primary sclerosing cholangitis. Gut 1996;38:610-15.

32 Porayko MK, Wiesner RH, LaRusso NF, et al. Patients with asymptomatic primary sclerosing cholangitis frequently have progressive disease. Gastroenterology 1990;98: 1594-602

33 Pasha TM, Petz JL, Ludwig J, et al. Incidence of cholangiocarcinoma in patients with primary sclerosing cholangitis. Hepatology 1997;26:170A.

34 Bergquist A, Glaumann H, Persson B, et al. Risk factors and clinical presentation of hepatobiliary carcinoma in patients with primary sclerosing cholangitis: a case-control study. Hepatology 1998;27:311-16.

35 Andersson RE, Olaison G, Tysk C, et al. Appendectomy and protection against ulcerative colitis. N Engl J Med 2001;344:808-14.
36 Reif S, Lavy A, Keter D, et al. Appendectomy is more frequent but not a risk factor in Crohn's disease while being protective in ulcerative colitis: a comparison of surgical procedures in inflammatory bowel disease. Am J Gastroenterol 2001;96:829-32.

37 Gorman P, Bennett D, Kavanagh E, et al. MALTectomy (appendectomy/tonsillectomy) does not influence the occurrence or mode of presentation of adult celiac disease. Am J Gastroenterol 1996;91:723-5

38 George J, Levy Y, Shoenfeld Y. Smoking and immunity: an additional player in the mosaic of autoimmunity. Scand J Immunol 1997:45:1-6.

39 Srivastava ED, Barton JR, Mahony S, et al. Smoking, humoral immunity, and ulcerative colitis. Gut 1991;32:1016-19.

40 Prytz H, Benoni C, Tagesson C. Does smoking tighten the gut? Scand J Gastroenterol 1989;24:1084-8.

41 Pullan RD. Colonic mucus, smoking and ulcerative colitis. Ann R Coll Surg Engl 1996;78:85-91.

42 Srivastava ED, Russell MA, Feyerabend C, et al. Effect of ulcerative colitis and smoking on rectal blood flow. Gut 1990;31:1021-4

43 Motley RJ, Rhodes J, Williams G, et al. Smoking, eicosanoids and ulcerative colitis. J Pharm Pharmacol 1990;42:288-9.

44 Zijlstra FJ, Srivastava ED, Rhodes $M$, et al. Effect of nicotine on rectal mucus and mucosal eicosanoids. Gut 1994;35:247-51.

45 Zijlstra FJ. Smoking and nicotine in inflammatory bowel disease: good or bad for cytokines? Mediators Inflamm 1998;7:153-5.

46 Baron JA, Comi RJ, Cryns V, et al. The effect of cigarette smoking on adrenal cortical hormones. J Pharmacol Exp Ther 1995;272:151-5.

47 Reif S, Lavy A, Keter D, et al. Lack of association between smoking and Crohn's disease but the usual association with ulcerative colitis in Jewish patients in Israel: a multicenter study. Am J Gastroenterol 2000;95:474-8. 